\title{
BMJ Open Analysis of HLA-B15 and HLA-B27 in spondyloarthritis with peripheral and axial clinical patterns
}

John Londono, ${ }^{1}$ Ana Maria Santos, ${ }^{1}$ Paola Peña, ${ }^{1}$ Enrique Calvo, ${ }^{2}$ Luis R Espinosa, ${ }^{3}$ John D Reveille, ${ }^{4}$ Gilberto Vargas-Alarcon, ${ }^{5}$ Carlos A Jaramillo, ${ }^{6}$ Rafael Valle-Oñate, ${ }^{7}$ Mabel Avila, ${ }^{1,7}$ Consuelo Romero, ${ }^{7}$ Juan F Medina ${ }^{8}$

To cite: Londono J, Santos AM, Peña $P$, et al. Analysis of HLA-B15 and HLA-B27 in spondyloarthritis with peripheral and axial clinical patterns. BMJ Open 2015:5:e009092.

doi:10.1136/bmjopen-2015009092

- Prepublication history for this paper is available online. To view these files please visit the journal online (http://dx.doi.org/10.1136/ bmjopen-2015-009092).

Received 16 June 2015 Revised 8 September 2015 Accepted 30 September 2015

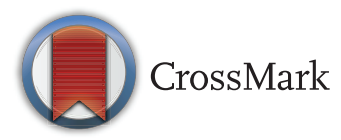

For numbered affiliations see end of article.

\section{Correspondence to}

Dr John Londono; john.londono@unisabana. edu.co

\section{ABSTRACT}

Objective: Human leucocyte antigen (HLA) B27 and HLA-B15 are associated with spondyloarthritis (SpA). Recent Assessment of SpondyloArthritis international Society (ASAS) criteria emphasise a distinction between SpA with axial and peripheral patterns. We analysed whether HLA-A, HLA-B and HLA-DRB1 alleles could associate with these patterns.

Methods: We studied 100 healthy individuals and 178 patients with SpA according to European Spondyloarthropathy Study Group (ESSG) criteria. Patients were then classified according to ASAS criteria, the axial spondyloarthritis pattern (axSpA) being defined by ascertained sacroiliitis and the peripheral pattern $(\mathrm{pSpA})$ by enthesitis and/or arthritis in extremities. A combined ax/p pattern was also considered.

Results: Only HLA-B27 and HLA-B15 alleles were associated with SpA. ASAS criteria for axSpA were met in 152 patients ( 12 with isolated axSpA and 140 with a combined ax/p patterns). When the ASAS peripheral criteria were applied, 161 patients met these criteria (13 with isolated $p S p A$ and 148 with a combined $a x / p$ pattern). HLA-B27 was found in $83 \%$ of patients with axSpA and $43 \%$ of ax/pSpA patients according to axASAS. HLA-B27 occurred in 7\% controls but not in any patient with isolated $\mathrm{pSpA}$. HLA-B15 was encountered in $31 \%$ of patients with isolated $\mathrm{pSpA}$ and $20 \%$ of ax/pSpA patients according to pASAS criteria. Moreover, 2 healthy controls, but none of our patients with isolated axSpA were positive for HLA-B15.

Conclusions: Our data suggest that the presence of HLA-B15 favours the development of isolated/ combined peripheral rather than isolated axSpA, while HLA-B27 promotes an isolated/combined axial disease and excludes a peripheral pattern. HLA-B15 should be considered in addition to HLA-B27 when diagnosing patients with SpA according to ASAS criteria.

\section{INTRODUCTION}

Spondyloarthritis (SpA) comprises a group of inflammatory chronic diseases that share similar clinical presentations, radiological findings, human leucocyte antigen (HLA)

\section{Strengths and limitations of this study}

- Human leucocyte antigen (HLA) HLA-B15 has been associated with spondyloarthritis $(\mathrm{SpA})$ and oligoarthritis in different populations. This study clearly establishes this association through a detailed analysis of the clinical and radiological aspects in a group of patients of non-Anglo-Saxon origin.

- In this study, conducted on a group of Latin American patients with $\mathrm{SpA}$, the presence of HLA-B15 and HLA-B27 clearly influence the pattern of presentation of the disease. HLA-B15 favours a preferably peripheral pattern while HLA-B27 promotes an isolated/combined axial disease and excludes an isolated peripheral pattern.

- HLA-B15 should be considered in addition to HLA-B27 when diagnosing Colombian patients with SpA according to ASAS criteria.

- This study used the ASAS criteria in an alternating manner to discriminate the association of the disease with HLA-B27 and HLA-B15.

- The results of this study need to be verified in further research studies involving a larger number of patients with SpA.

B27 association and positive family history. ${ }^{1}$ According to the European Spondyloarthropathy Study Group (ESSG) criteria, ${ }^{2} \mathrm{SpA}$ has been traditionally classified as follows: ankylosing spondylitis (AS), reactive arthritis (ReA), undifferentiated SpA (uSpA), psoriatic arthritis and arthritis associated with inflammatory bowel disease (IBD).$^{3}$ Its prevalence varies from $0.1 \%$ to $1.4 \%$ of the general population depending on the geographical region studied. ${ }^{4}$ Despite the fact that SpA tends to affect males more frequently and severely than it does females, an increasing proportion of female patients has being observed during the last decade among patients with less severe clinical manifestations. ${ }^{5}$ Predominantly, SpA begins in 
individuals younger than 45 years of age and clinically compromises the axial spine, peripheral joints, tendons and ligament insertions (entheses), and also has extra musculoskeletal manifestations in the skin, mucosa, gut and the eyes. ${ }^{6}$

HLA-B27 is the biggest risk factor for the development of SpA, and while it does have a central role in its aetiopathogenesis, the association is not the same across all ethnic groups. ${ }^{7}$ It has been estimated that this allele is responsible for up to $28 \%$ of the aetiology of $\mathrm{SpA}{ }^{8}$ However there are other factors that have an impact on the onset of the disease, such as environmental factors, and other genetic factors, including those within the major histocompatibility complex (MHC) class I-HLA-B60/HLA-B40, ${ }^{9}$ HLA-B39, ${ }^{10}$ HLA-B14, ${ }^{11}$ and HLA-B $15^{12}$ - and class II-DRB $1^{13}$-alleles.

Current new technologies are allowing early diagnosis and more specific examination of disease susceptibility, such as those that look at single nucleotide polymorphisms (SNPs), genome-wide association studies and genomic resequencing, which underscore the polygenic nature of SpA. ${ }^{14}{ }^{15}$ There are more than 40 genes implicated in the pathogenesis of SpA, which may also affect the clinical manifestations, including the age of onset and the duration and severity of the disease. ${ }^{16}$

The diagnosis of SpA is made principally based on clinical, radiological and laboratory findings. The classification currently proposed by the European League Against Rheumatism (EULAR) and the Assessment of SpondyloArthritis international Society (ASAS) shows a high sensitivity and specificity $(79.5 \%$ and $83.3 \%$, respectively). ${ }^{1718}$ According to these entities, SpA can have two general clinical patterns: axial and peripheral. With these two clinical patterns, there may be a genetic variability that accounts for each physical distribution. In fact, data emerging from immunopathological studies and from clinical trials suggest that the pathogenesis of axial and peripheral disease may be caused by different mechanisms influenced by genetic differences, a situation that underscores the importance of the new clinical classification criteria from ASAS for peripheral and axial SpA. ${ }^{19}$ The axial criteria rely on two major components, imaging and the presence of HLA-B27. ${ }^{20}$ The latter was adopted because of its high sensitivity and specificity, and its extensive validation for axSpA. However, the validity of the HLA-B27 component is less defined for pSpA and uSpA. In uSpA with peripheral involvement, for instance, about $60 \%$ of patients are negative for HLA-B27. ${ }^{21}$ However, previous studies in patients with SpA have reported an association with HLA-B15 in Europe (Belgium), ${ }^{22}$ North Africa (Tunisia) ${ }^{23}$ and Latin America (Mexico), ${ }^{24}$ where the most common presentations of SpA were related to IBD, ReA and uSpA. In particular, peripheral involvement was nearly ubiquitous in these cohorts. This would suggest that the HLA-B15 allele may play an important role in the susceptibility to peripheral $\mathrm{SpA} .^{25}$

The objective of this study was to evaluate the impact of HLA-B15 and HLA-B27 alleles on the susceptibility and clinical characteristics of the disease (considered according to either ESSG or ASAS criteria) in a Colombian population with SpA.

\section{PATIENTS AND METHODS}

\section{Participants and clinical assessment of patients}

A group of 178 patients with a diagnosis of SpA according to the ESSG criteria were studied. These patients were seen in the Central Military Hospital in Bogota, Colombia, between January 2005 and December 2011. All patients were evaluated by a rheumatologist in the outpatient care department, with subsequent HLA genotyping. Demographic and clinical data, including disease activity (graded through the Bath Ankylosing Spondylitis Disease Activity Index, BASDAI ${ }^{26}$ as well as the global disease activity assessed by the physician, that is, the visual analog scale of the physician's global assessment of disease activity, abbreviated as VAS physician, ${ }^{27}$ the VAS global disease activity assessed by patients, abbreviated as VAS patient, ${ }^{27}$ and the VAS of Inflammatory Back Pain, abbreviated as VAS IBP, ${ }^{27}$ functional capacity (graded through the Bath Ankylosing Spondylitis Functional Index, BASFI), ${ }^{28}$ inflammatory back pain, enthesitis and joints affected, were recorded. Recommendations for follow-up were according to the previously validated ASAS guidelines. ${ }^{27}$ Each enthesis was evaluated using the Mander's enthesis index. ${ }^{29}$ For each patient, laboratory examinations that included the erythrocyte sedimentation rate were taken.

The control group consisted of 100 healthy subjects on the list of transplant donors at the Central Military Hospital in Bogota, Colombia. These participants had the same sociodemographic characteristics as our SpA population. Cases and controls were compared for the Hardy-Weinberg equilibrium, as tested with the Arlequin statistical software V.3.5. ${ }^{30}$ Allele frequency among the patient population was calculated using Genepop software. ${ }^{31}$

\section{Ethics approval}

The study followed the norms established by the Helsinki Declaration, The Guidelines for Good Clinical Practice and Resolution 8430 (1993) of the Colombian Ministry for Social Protection. Moreover, it was reviewed and approved by the Ethics Committees of the University of La Sabana, Los Andes University and the Central Military Hospital. Each patient signed an informed consent form and confidentiality was strictly maintained.

\section{Imaging}

A plain anterior pelvic X-ray was taken along with MRI of the sacroiliac joints with $\mathrm{T} 1$ sequence and fat suppression technique for each patient. This was then read by a radiologist with musculoskeletal expertise who was blinded to the clinical picture. An interpretation of the X-rays was made following the recommendations for 
population studies in the Atlas of Standard Radiographs, ${ }^{32}$ and the MRI was evaluated looking for acute and chronic changes in the joints. ${ }^{33}$

\section{HLA genotyping}

Genomic DNA was extracted from peripheral blood leucocytes using a Wizard genomic DNA purification Kit (Promega, Cat \# A1120). After extraction, samples were adjusted to a DNA concentration ranging $80-200 \mathrm{ng} / \mu \mathrm{L}$ and stored at $-80^{\circ} \mathrm{C}$ until processing of HLA. Typing was carried out by PCR on the genomic DNA using a HLA sequence-specific primer (SSP) HLA-ABDR-SSPtray Kit (BioRad, Cat \# 826 230), which was focused on determining the HLA-A, HLA-B and DRB1 alleles. PCR products were verified by electrophoresis in a $2 \%$ agarose gel, and bands were visualised by ultraviolet light photo documentation and further analysed using HLA-SSP Typing V. 1.2.0.0 software (BioRad).

\section{Statistical analyses}

Data are expressed as mean \pm SD (except where otherwise indicated). For statistical analysis we used SPSS V.19.0 (SPSS Inc). For the presentation and analysis of categorical variables, frequency distribution, percentages and contingency tables were used. Comparisons were made using the $\chi^{2}$ and Fisher exact tests. For numerical values, central tendency and dispersion measurements were evaluated. Results were analysed using Student $\mathrm{t}$ and
Wilcoxon tests. Two-tailed $\mathrm{p}$ values $<0.05$ were considered statistically significant. The association between disease and HLA alleles was determined by OR and CIs of $95 \%$ (OR: 95\% CI).

\section{RESULTS}

\section{Genotype and demographic data}

Only HLA-B27 and HLA-B15 of all the analysed HLA-A, HLA-B and HLA-DRB1 alleles were found to be significantly associated with SpA. As shown in table 1, our 178 patients with SpA (included in the study because they met the ESSG criteria) could therefore be divided into three groups according to their HLA-B genotype: 34 patients $(19.1 \%)$ had HLA-B15, 70 (39.3\%) showed HLA-B27 and $74(41.6 \%)$ had other HLA-B alleles. Patients with HLA-B15 and HLA-B27 had an earlier age of disease onset than patients with other HLA-B alleles. However, the earlier age was only significant considering the patients with HLA-B27 $(\mathrm{p}=0.008)$. A male predominance (with a male/female ratio of $3.7 / 1$ ) was documented in the group of 70 patients positive for HLA-B27, whereas females were slightly predominating (male/female ratio: $0.8 / 1$ ) in the group of 34 patients positive for HLA-B15. In this regard, however, the statistical difference between these two groups (ie, patients with HLA-B27 and HLA-B15) was highly significant (table 1).

Table 1 Demographic and clinical stratification of patients with $\mathrm{SpA}$ in relation to their HLA-B genotype

\begin{tabular}{|c|c|c|c|c|}
\hline Variable & HLA-B15 (n=34) & HLA-B27 (n=70) & Other HLA-B $(n=74)$ & $\begin{array}{l}\text { Significant } \\
p \text { values }\end{array}$ \\
\hline Age $\pm S D-$ years, mean $\pm S D(n=178)$ & $35.7 \pm 10.0$ & $35.8 \pm 13.6$ & $35.8 \pm 13.1$ & \\
\hline Age of onset-years, mean $\pm S D(n=178)$ & $28.2 \pm 9.4$ & $27.7 \pm 10.5$ & $32.6 \pm 10.9$ & $0.008^{*}$ \\
\hline Disease duration-years, median (IQR) & $3.4(2-12)$ & $3.6(1-12)$ & $3.0(1-11.5)$ & \\
\hline Sex-number of men/women (\%) & $15 / 19(44 / 56)$ & $55 / 15(79 / 21)$ & $30 / 44(40 / 60)$ & $0.001 \dagger$ \\
\hline Men:women ratio & $0.8: 1$ & $3.7: 1$ & $1.46: 1$ & \\
\hline \multicolumn{5}{|c|}{ Patients with SpA classified according to ESSG criteria } \\
\hline Patients having AS $(n=91)$ & 13 & 41 & 37 & \\
\hline Patients having uSpA $(n=57)$ & 17 & 15 & 25 & $0.006 \ddagger$ \\
\hline Patients having $\operatorname{ReA}(n=30)$ & 4 & 14 & 12 & \\
\hline Total $(n=178)$ & 34 & 70 & 74 & \\
\hline \multicolumn{5}{|c|}{ Patients with SpA classified according to ASAS criteria } \\
\hline Patients with axSpA manifestations $(n=152) \S$ & 27 & 70 & 55 & $<0.0001 \rrbracket$ \\
\hline Patients with isolated axSpA $(n=12)$ & 0 & 10 & 2 & $0.050^{\star *}$ \\
\hline Patients with combined ax/pSpA $(n=140)$ & 27 & 60 & 53 & \\
\hline Patients with $\mathrm{pSpA}$ manifestations $(n=161) \dagger \dagger$ & 34 & 60 & 67 & $0.050 \ddagger \ddagger$ \\
\hline Patients with isolated $\mathrm{pSpA}(n=13)$ & 4 & 0 & 9 & $0.015 \S \S$ \\
\hline Patients with combined ax/pSpA $(n=148)$ & 30 & 60 & 58 & \\
\hline
\end{tabular}

Percentages within parenthesis are calculated with respect to the number of patients in each HLA-B group.

Shown significant $p$ values correspond as follows.

${ }^{*} \mathrm{p}=0.008$, between HLA-B27 and other HLA-B; $\dagger \mathrm{p}<0.001$, both between HLA-B27 and HLA-B15, and between HLA-B27 and other HLA-B alleles; there was no significant difference between HLA-B15 and other HLA-B; $\neq p=0.006$, between HLA-B15 and HLA-B27; $\S(n=152)$, among our 178 patients satisfying the ESSG classification criteria for SpA, ${ }^{2}$ only 152 met the ASAS criteria for axSpA ${ }^{18}$ and 26 patients did not; I $\mathrm{p}<0.0001$, between HLA-B27 and other HLA-B; ${ }^{* *} \mathrm{p}=0.050$, between HLA-B15 and HLA-B27; $\dagger+(\mathrm{n}=161)$ indicates that 161 patients (but not the remaining 17 patients) met the ASAS criteria for $p S p A .{ }^{17} \ddagger \ddagger p=0.050$, between HLA-B27 and HLA-B15; $\S \S p=0.015$, between HLA-B15 and HLA-B27.

AS, ankylosing spondylitis; ASAS, Assessment of SpondyloArthritis international Society; axSpA, axial spondyloarthritis; ESSG, European Spondyloarthropathy Study Group; HLA, human leucocyte antigen; pSpA, peripheral spondyloarthritis; uSpA, undifferentiated spondyloarthritis; ReA, reactive arthritis; SpA, spondyloarthritis. 
When ASAS classification criteria ${ }^{17} 18$ were applied to classify 178 patients previously diagnosed according to the ESSG criteria, 152 patients fulfilled the ASAS criteria for axSpA while 26 did not, and 161 patients met the ASAS criteria for pSpA while 17 did not. Most of the patients meeting the ASAS criteria for axSpA and/or pSpA manifested a combined ax/p patterns, though the total number of these patients slightly fluctuated. This fluctuation was dependent on the application to our patients of either the axial or peripheral criteria (table 1), these two sets of ASAS criteria being simultaneously met in 137 patients. Moreover, 12 patients had isolated axSpA and 13 showed isolated pSpA (table 1). Noticeably, $100 \%$ of the 70 patients positive for HLA-B27 included in the study exhibited axial manifestations of the disease (mainly back pain) and $100 \%$ of the 34 patients positive for HLA-B15 had peripheral manifestations of SpA (mainly join arthritis). Among the 12 patients with isolated axSpA, $10(83 \%)$ were positive for HLA-B27, and among the 13 patients with isolated pSpA, $4(31 \%)$ were positive for HLA-B15. Moreover, HLA-B27 was absent in all 13 patients with pSpA (table 1), though this allele did occur in $7 \%$ of the 100 healthy control subjects (not shown). Finally, while two healthy controls $(2 \%)$ were positive for HLAB-15, none of the 12 axSpA were positive for this allele. Further demographic data and clinical presentation related to either ESSG or ASAS criteria and to HLA-B27, HLA-B15 and other $\mathrm{B}$ alleles are also shown in table 1.

\section{Association of HLA-B15 and HLA-B27 alleles to clinical SpA subsets}

When patients with SpA were analysed as a whole, we found a statistical association of the disease with both HLA-B15 and HAL-B27 (table 2). However, when the clinical subsets were considered, HLA-B15 was found to be mainly associated with $\mathrm{uSpA}$ and $\mathrm{pSpA}$ forms, whereas HLA-B27 was mainly associated with AS (table 2).

\begin{tabular}{lll}
$\begin{array}{l}\text { Table } 2 \\
\text { subsets }\end{array}$ & Association of HLA-B15 and HLA-B27 with SpA \\
\hline \multicolumn{4}{c}{ HLA-B15 } & HLA-B27 \\
Disease & OR $(95 \%$ Cl) & OR (95\% Cl) \\
\hline SpA & $14.9^{*}(3.4$ to 90.8$)$ & $9.1^{*}(3.8$ to 22.8$)$ \\
SpA subsets according to ESSG criteria \\
AS & $13.2^{*}(2.8$ to 85.1$)$ & $15.7^{*}(6.1$ to 41.8$)$ \\
USpA & $20.9^{*}(4.4$ to 134.9$)$ & $13.8(1.4$ to 11.2$)$ \\
ReA & $10.1(1.7$ to 77.3$)$ & $11.2^{*}(2.7$ to 35.3$)$ \\
SpA subsets according to ASAS criteria \\
axSpA & $8.2^{*}(1.9$ to 35.6$)$ & $9.8^{*}(4.3$ to 22.5$)$ \\
pSpA & $15.4^{*}(3.6$ to 65.4$)$ & $7.0^{*}(3.1$ to 16.1$)$ \\
\hline
\end{tabular}

${ }^{*} \mathrm{p}<0.05$, patients versus controls by $\chi^{2}$ tests.

AS, ankylosing spondylitis; ASAS, Assessment of

SpondyloArthritis international Society; axSp, axial spondyloarthritis; ESSG, European Spondyloarthropathy Study Group; HLA B, human leucocyte antigen; $p S p A$, peripherial spondyloarthritis; ReA, reactive arthritis; $\mathrm{SpA}$, spondyloarthritis; uSpA, undifferentiated spondyloarthritis.
The relationships of HLA-B27 and HLA-B15 with clinical forms of presentation according to either the ESSG criteria or the ASAS criteria are further summarised in figure 1. This figure graphically illustrates our findings that none of the patients with isolated axial $\mathrm{SpA}$ are HLA-B15 positive and that HLA-B27 does not occur in patients with only peripheral SpA. These findings appear to strengthen the notion that ASAS criteria might have allowed a better correlation between the clinical presentation of SpA and the HLA-B genotype than the ESSG criteria did.

\section{HLA-B15 and HLA-B27 alleles and disease characteristics}

The most relevant clinical features and radiological findings in relation to HLA alleles are shown in figure 2. Remarkably, patients with HLA-B15 had more swollen joints $(5.3 \pm 5.1$ vs $2.3 \pm 1.8, \mathrm{p}=0.004)$, and total count of painful enthesitis $(6.0 \pm 4.5$ vs $4.3 \pm 3.3, \mathrm{p}=0.014)$ and peripheral painful enthesitis $(3.4 \pm 2.9$ vs $2.3 \pm 2.2, \mathrm{p}=0.050)$, while patients positive for HLA-B27 had more frequent sacroiliitis of grade $\geq 2(74.7 \%$ vs $56.3 \%, \mathrm{p}=0.043)$ and enthesitis in the sacroiliac region $(64.4 \%$ vs $36 \%$, $\mathrm{p}=0.001$ ).

\section{HLA-B15 and HLA-B27 alleles and disease activity}

When disease activity was taken into account, we found that patients positive for HLA-B15 had a higher rate in the BASDAI index, BASFI index and global disease activity assessed by physician (VAS physician) compared to patients positive for HLA-B27 (figure 3). However, patients positive for HLA-B27 had a higher rate in inflammatory back pain and global disease activity assessed by patient (VAS patient) than patients positive for HLA-B15 (figure 3). Finally, it is noteworthy to

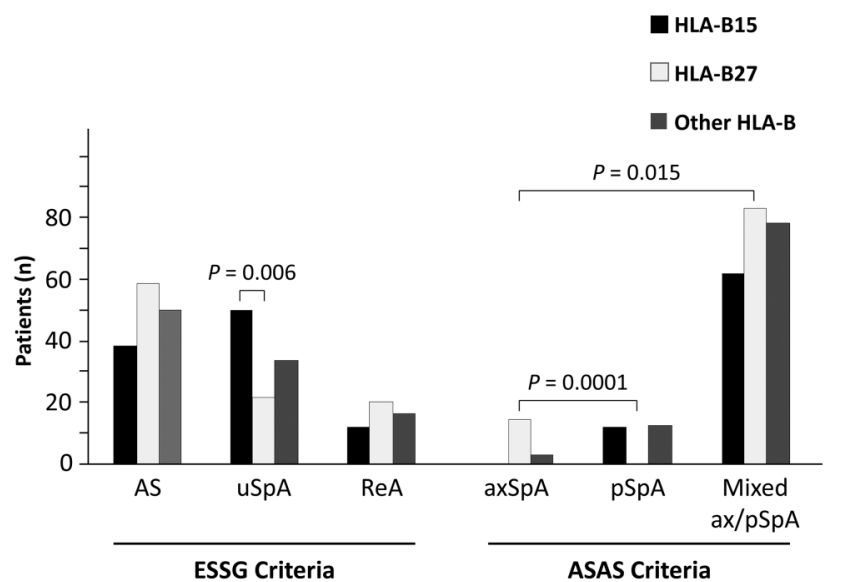

Figure 1 Spondyloarthritis ( $\mathrm{SpA}$ ) classification criteria in relation to human leucocyte antigen (HLA) B15 or HLA-B27. The European Spondyloarthropathy Study Group classification criteria for spondyloarthropathy (ESSG) criteria: ankylosing spondylitis (AS), undifferentiated spondyloarthritis (uSpA), and reactive arthritis (ReA). The Assessment of SpondyloArthritis international Society (ASAS) criteria: axial spondyloarthritis (axSpA) and peripheral spondyloarthritis (pSpA). 

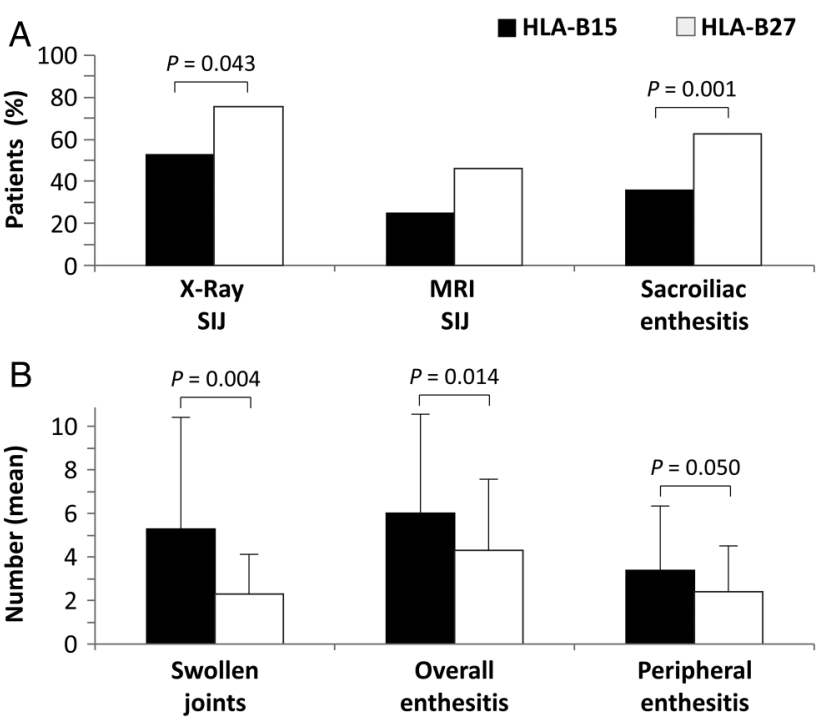

Figure 2 Spondyloarthritis (SpA) manifestations in patients positive for human leucocyte antigen (HLA) B15 or HLA-B27. (A) Percentage of patients with joint abnormalities in relation to their genotype: sacroiliac joint $(\mathrm{SIJ})$ inflammation grade $\geq 2$ as assessed by X-ray of the pelvis (X-ray SIJ), acute changes detected by nuclear MRI in sacroiliac joint (MRI SIJ), enthesitis in sacroiliac region assessed by Mander enthesis index (sacroiliac enthesitis). (B) Mean number of joints affected in each patient in relation to the respective HLA-B genotype: swollen joints, mean number of joints that are swollen on assessment of 66 joints in each patient; Overall enthesitis: mean of total (axial and peripheral) entheses affected; peripheral enthesitis: mean of peripheral entheses affected.

mention that patients positive for HLA-B27 exhibited a higher erythrocyte sedimentation rate than patients positive for HLA-B15 did $(25.7 \pm 24.4 \mathrm{~mm} / \mathrm{h}$ vs $16.5 \pm 9.8$, respectively).

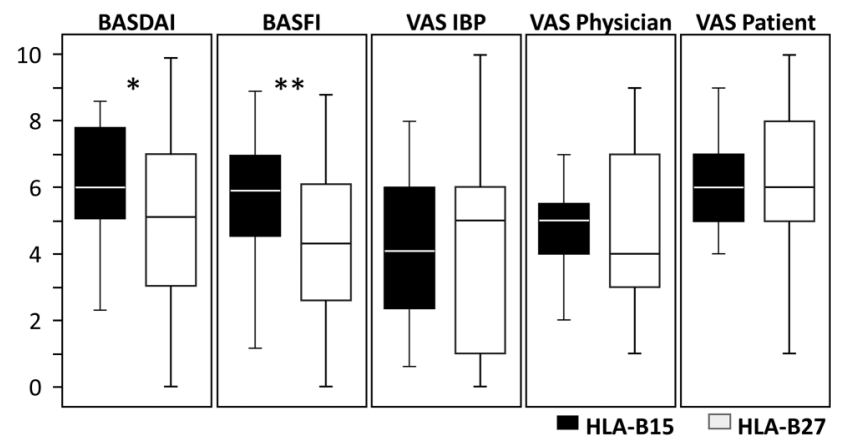

Figure 3 Grading of disease activity in relation to human leucocyte antigen (HLA) B15 or HLA-B27. Bath Ankylosing Spondylitis Disease Activity Index (BASDAI), Bath Ankylosing Spondylitis Functional Index (BASFI), visual analog scale of patient's global assessment of disease activity (VAS Patient), visual analog scale of physician's global assessment of disease activity (VAS Physician,), visual analog scale of inflammatory back pain (VAS IBP). Each score ranges from 0 to 10; median and 25th and 75th centiles are shown; ${ }^{\star} p<0.0001,{ }^{\star \star} p=0.009$ (Student $t$ test).

\section{DISCUSSION}

In this study, we found that, in addition to the strong association of SpA with HLA-B27, SpA can be associated with another HLA-B allele, that is, with HLA-B15. Noticeably, the prevalence of HLA-B15 was particularly increased in patients with $\mathrm{SpA}$ with peripheral involvement. Moreover, while patients with HLA-B27 were more likely to be male and to show axial compromise associated with AS, HLA-B15 positive patients had a lower proportion of men and a more frequent uSpA clinical manifestation.

Patients with either HLA-B15 or HLA-B27 had similar ages of disease onset and comparable duration of the disease. From a clinical point of view, patients with HLA-B15 had an increased number of peripheral joints affected than patients with HLA-B27, while no differences in spinal mobility were observed between these two groups of patients. Radiographically, patients with HLA-B27 showed more severe sacroiliitis in pelvic X-rays and greater acute damage in MRI than patients positive for HLA-B15 did.

Male gender, axial involvement, early age of disease onset ( $<20$ years), and the presence of HLA-B27 are all known to be associated with a bad prognosis. ${ }^{34}$ In our study, patients with HLA-B15 (consisting of slightly fewer males than females) exhibited a less severe disease phenotype and more peripheral symptoms as compared with patients positive for HLA-B27. Concerning the disease activity in our patients, however, both BASDAI and BASFI scores were higher (worse) in HLA-B15 positive patients than in those with HLA-B27. This may be related to important functional impairment and higher inflammatory disease activity in a greater number of lower extremity joints, and enthesitis in the HLA-B15 group. ${ }^{35}$ However, the acute phase reactants were particularly increased in the patients positive for HLA-B27.

HLA-B27 has been known for over 40 years as a predisposing factor for $\mathrm{SpA}$, specifically for AS. ${ }^{37}$ In Caucasians with $\mathrm{SpA}, 80-85 \%$ of patients are HLA-B27 positive. Overall, however, $<5 \%$ of Caucasian individuals with this allele go on to develop the disease. ${ }^{38}$ This suggests that, even though HLA-B27 appears to play a major role in the development of the disease, it is not enough to completely explain the disease susceptibility. In fact, in populations other than Caucasian, HLA-B27 may be less prevalent. Thus, in the Mestizo population, which has arisen from a mix of pre-Columbian indigenous individuals with Spanish Caucasians and African-Americans, HLA-B27 has been reported in between $40 \%$ and $60 \%$ of patients with SpA. ${ }^{39} 40$ This is further confirmed in our present study population, in which 70 of 178 patients with $\mathrm{SpA}(39.3 \%)$ were positive for HLA-B27.

In people of Anglo-Saxon descent, AS is the most common subtype of SpA, while uSpA is the predominant subtype in the Latin American Mestizo population. ${ }^{40}$ This variation could be due to associations of the disease with different HLA genes in addition to HLA-B27. ${ }^{41}$ The new criteria recently proposed by ASAS to classify SpA allow for grouping of patients according to severity, 
onset and axial or peripheral pattern of the disease. It is remarkable that in our study, $100 \%$ of the patients positive for HLA-B15 met with the ASAS peripheral criteria and $100 \%$ of the HLA-B27 positives fulfilled the ASAS axial criteria.

There had been previous reports partially considering the HLA-B15 allele in relation to SpA. Thus, a study in a Mexican population, in addition to showing a strong association of HLA-B27 with SpA, also suggested that prevalence of HLA-B15 was increased in the whole SpA cohort. ${ }^{24}$ In fact, HLA-B15 was modestly increased in uSpA but not in patients with AS, whereas HLA-B27 showed a greater association with AS than with uSpA. ${ }^{24}$ Likewise, a prospective study in Belgium examined patients with different subtypes of SpA, and found that HLA-B15 was more frequent in those patients with uSpA $(16 / 51,32 \%)$ as well as in those with a clinical remission of symptoms. ${ }^{42}$ HLA-B27, however, was more prevalent in those patients with AS and in those with sustained disease activity. Also, in Tunisia, HLA-B15 was associated with uSpA as well as with ReA. In fact, this allele was found in up to $50 \%$ of patients with uSpA. As this observation is very similar to previous studies carried out in Latin America, Europe and Africa, it was suggested that it could be the result of population migrations. ${ }^{43}$ The aforementioned data indicate that HLA-B15 is found in various different ethnic groups, crossing geographical barriers, and altogether these data further support the notion that HLA-B15 plays a role in SpA pathogenesis. ${ }^{44}$

Inflammatory diseases other than SpA have also been associated with HLA-B15. A meta-analysis in a Caucasian population with acute periodontitis showed a strong association with this allele. ${ }^{45}$ Moreover, there seems to be a relationship between periodontal disease and the onset of inflammatory diseases such as rheumatoid arthritis, which suggests that HLA-B15 may be related to acute and chronic diseases with local bone involvement. ${ }^{45}$ Furthermore, HLA-B15 was found to be associated with Behçet's disease in a Moroccan population, where females were the dominant affected population. ${ }^{46}$

HLA-B15 is an MHC class I molecule encoded by multiple polymorphic alleles leading to at least 7 serological subtypes. ${ }^{44}$ Variants have been described-with either tyrosine or serine at position 116 - that greatly diverge in their interaction (either strong or weak, respectively) with other proteins in the endoplasmic reticulum for antigen presentation at the cell surface. ${ }^{47}$ Accordingly, it might be expected that genetic diversity can contribute to increased or decreased predisposition to autoimmune diseases. In the case of HLA-B15, recent studies have demonstrated that this molecule, as well as HLA-B14, HLA-B38, HLA-B39 and HLA-B73, all have an unpaired free cysteine (at position 67) in the B pocket of the $\alpha$-heavy chain, which is very similar to HLA-B27. This may allow for the formation of homodimers that could activate the innate immune response to produce cytokines implicated in chronic inflammation in the pathogenesis of $\mathrm{SpA}{ }^{48}$
Recently, a high-density genotyping study was carried out to identify multiple risk variants for AS. ${ }^{15}$ In addition to confirming the previously reported strong association of the disease with SNPs at the gene for the endoplasmic reticulum aminopeptidase 1 (ERAP1), which was restricted to AS patients positive for HLA-B27, this study found a significant association of AS with another member of the endoplasmic reticulum aminopeptidase family, ERAP2, which prevailed in patients with AS negative for the HLA-B27 allele. ${ }^{15}$ Future highdensity genotyping studies might uncover whether some (or most) of these-patients negative for HLA-B27 are positive for the HLA-B15 allele. While ERAP1 seems to play a critical role in determining the length and sequence of the peptides bound and presented by HLA-B27 associated with AS, ${ }^{49}$ it might be desirable to hypothesise that ERAP2 may play a parallel role in the context of HLA-B15.

\section{CONCLUSIONS}

Our study with a Mestizo cohort indicates that HLA-B15 is associated with the peripheral manifestation of SpA independently of sex or age, with a notable involvement of joints and enthesitis, and with minor axial compromise. HLA-B15 may therefore become an important tool and marker for the disease in our population, particularly in those patients with peripheral SpA without HLA-B27.

\section{Author affiliations}

${ }^{1}$ Department of Rheumatology, University of La Sabana, Chia, Cundinamarca, Colombia

${ }^{2}$ Department of Radiology, National University of Colombia, Bogota, Colombia ${ }^{3}$ LSU Health Sciences Center, Louisiana State University, New Orleans, Louisiana, USA

${ }^{4}$ Division of Rheumatology and Clinical Immunogenetics, Department of Internal Medicine, University of Texas Health Science Center, Houston, Texas, USA

${ }^{5}$ Interventional Genetic Study Group in Cardiovascular Diseases, Department of Molecular Biology, National Institute of Cardiology Ignacio Chávez, Mexico DF, Mexico

${ }^{6}$ Department of Biological Sciences, University of Los Andes, Bogota, Colombia

${ }^{7}$ Rheumatology and Immunology Unit, Department of Internal Medicine, Hospital Militar Central, Bogota, Colombia

${ }^{8}$ Department of Internal Medicine, School of Medicine, University of Navarra and Ciberehd, Pamplona, Spain

\section{Twitter Follow JOHN LONDONO at @Iondonojohn}

Acknowledgements The authors would like to acknowledge to Maria del Pilar Delgado, MSs, Department of Biological Sciences, University of Los Andes, for critical review of the manuscript.

Contributors All the authors were involved in drafting the article or revising it critically for important intellectual content and approved the final version to be published. JL had full access to all of the data in the study and takes responsibility for the integrity of the data and the accuracy of the data analysis. JL, AMS, JFM, GV-A, LRE, JDR, CAJ, MA, CR and RV-0 were involved in study conception and design. JL, AMS and PP were responsible for acquisition of data. JL, AMS, PP and JFM participated in analysis and interpretation of data. 
Funding This work was supported by the University of La Sabana and the University of Los Andes.

Competing interests None declared.

Patient consent Obtained.

Ethics approval Ethics Committees of the University of La Sabana, Los Andes University and The Central Military Hospital.

Provenance and peer review Not commissioned; externally peer reviewed.

Data sharing statement Additional data can be accessed via the Dryad data repository at http://datadryad.org/ with the doi:10.5061/dryad.kb1p0.

Open Access This is an Open Access article distributed in accordance with the Creative Commons Attribution Non Commercial (CC BY-NC 4.0) license, which permits others to distribute, remix, adapt, build upon this work noncommercially, and license their derivative works on different terms, provided the original work is properly cited and the use is non-commercial. See: http:// creativecommons.org/licenses/by-nc/4.0/

\section{REFERENCES}

1. Khan MA. Update on spondyloarthropathies. Ann Intern Med 2002;136:896-907.

2. Dougados $\mathrm{M}$, van der Linden $\mathrm{S}$, Juhlin $\mathrm{R}$, et al. The European Spondylarthropathy Study Group preliminary criteria for the classification of spondylarthropathy. Arthritis Rheum 1991;34:1218-27.

3. Dougados M, van der Heijde D. Ankylosing spondylitis: how should the disease be assessed? Best practice \& research. Clin Rheumato 2002:16:605-18.

4. Ehrenfeld M. Geoepidemiology: the environment and spondyloarthropathies. Autoimmun Rev 2010;9:A325-9.

5. Haroon NN, Paterson JM, Li P, et al. Increasing proportion of female patients with ankylosing spondylitis: a population-based study of trends in the incidence and prevalence of AS. BMJ open $2014 ; 4$ e006634.

6. Dougados $\mathrm{M}$, Hochberg MC. Why is the concept of spondyloarthropathies important? Best practice \& research. Clin Rheumatol 2002;16:495-505.

7. Gonzalez-Roces S, Alvarez MV, Gonzalez S, et al. HLA-B27 polymorphism and worldwide susceptibility to ankylosing spondylitis. Tissue Antigens 1997;49:116-23.

8. Reveille JD. Genetics of spondyloarthritis-beyond the MHC Nat Rev Rheumatol 2012;8:296-304.

9. Robinson WP, van der Linden SM, Khan MA, et al. HLA-Bw60 increase susceptibility to ankylosing spondylitis in HLA-B27+ patients. Arthritis Rheum 1989;32:1135-41.

10. Yamaguchi A, Tsuchiya N, Mitsui $\mathrm{H}$, et al. Association of HLA-B39 with HLA-B27-negative ankylosing spondylitis and pauciarticular juvenile rheumatoid arthritis in Japanese patients. Evidence for a role of the peptide-anchoring B pocket. Arthritis Rheum 1995;38:1672-7.

11. Diaz-Peña R, Blanco-Gelaz MA, Njobvu $P$, et al. Influence of HLA-B*5703 and HLA-B*1403 on susceptibility to spondyloarthropathies in the Zambian population. J Rheumatol 2008;35:2236-40.

12. Wagener $P$, Zeidler $H$, Eckert $G$, et al. Increased frequency of HLA-Bw62 and Bw35 CREG antigens in HLA-B27 negative ankylosing spondylitis. Z Rheumatol 1984;43:253-7.

13. Brown MA, Kennedy LG, Darke C, et al. The effect of HLA-DR genes on susceptibility to and severity of ankylosing spondylitis. Arthritis Rheum 1998;41:460-5.

14. van Gaalen FA, Verduijn W, Roelen DL, et al. Epistasis between two HLA antigens defines a subset of individuals at a very high risk for ankylosing spondylitis. Ann Rheum Dis 2013;72:974-8.

15. Cortes A, Hadler J, Pointon JP, et al, International Genetics of Ankylosing Spondylitis Consortium (IGAS). Identification of multiple risk variants for ankylosing spondylitis through high-density genotyping of immune-related loci. Nat Genet 2013;45:730-8.

16. Diaz-Peña R, López-Vázquez A, López-Larrea C. Old and new HLA associations with ankylosing spondylitis. Tissue Antigens 2012;80:205-13.

17. Rudwaleit M, van der Heijde D, Landewé R, et al. The Assessment of SpondyloArthritis International Society classification criteria for peripheral spondyloarthritis and for spondyloarthritis in general. Ann Rheum Dis 2011;70:25-31.

18. Rudwaleit $M$, Landewé $R$, van der Heijde $D$, et al. The development of Assessment of SpondyloArthritis international Society classification criteria for axial spondyloarthritis (part I): classification of paper patients by expert opinion including uncertainty appraisal. Ann Rheum Dis 2009;68:770-6.

19. Baeten D, Breban M, Lories R, et al. Are spondylarthritides related but distinct conditions or a single disease with a heterogeneous phenotype? Arthritis Rheum 2013;65:12-20.

20. Rudwaleit M, van der Heijde D, Landewé R, et al. The development of Assessment of SpondyloArthritis international Society classification criteria for axial spondyloarthritis (part II): validation and final selection. Ann Rheum Dis 2009;68:777-83.

21. Valle-Oñate R, Candia L, Romero-Sánchez C, et al. Epidemiology of spondyloarthritis in Colombia. Am J Med Sci 2011;341:293-4.

22. Mielants $\mathrm{H}$, Veys EM, Joos $\mathrm{R}$, et al. HLA antigens in seronegative spondylarthropathies. Reactive arthritis and arthritis in ankylosing spondylitis: relation to gut inflammation. J Rheumatol 1987;14:466-71.

23. Siala M, Mahfoudh N, Fourati $\mathrm{H}$, et al. MHC class I and class II genes in Tunisian patients with reactive and undifferentiated arthritis. Clin Exp Rheumatol 2009;27:208-13.

24. Vargas-Alarcon G, Londono JD, Hernandez-Pacheco G, et al. Effect of HLA-B and HLA-DR genes on susceptibility to and severity of spondyloarthropathies in Mexican patients. Ann Rheum Dis 2002;61:714-17.

25. Reveille JD. An update on the contribution of the MHC to as susceptibility. Clin Rheumatol 2014;33:749-57.

26. Garrett S, Jenkinson T, Kennedy LG, et al. A new approach to defining disease status in ankylosing spondylitis: the Bath Ankylosing Spondylitis Disease Activity Index. J Rheumatol 1994;21:2286-91.

27. Sieper J, Rudwaleit M, Baraliakos X, et al. The Assessment of SpondyloArthritis international Society (ASAS) handbook: a guide to assess spondyloarthritis. Ann Rheum Dis 2009;68(Suppl 2): ii1-44.

28. Calin A, Garrett S, Whitelock H, et al. A new approach to defining functional ability in ankylosing spondylitis: the development of the Bath Ankylosing Spondylitis Functional Index. J Rheumatol 1994;21:2281-5.

29. Mander M, Simpson JM, McLellan A, et al. Studies with an enthesis index as a method of clinical assessment in ankylosing spondylitis. Ann Rheum Dis 1987;46:197-202.

30. Excoffier L, Lischer HE. Arlequin suite ver 3.5: a new series of programs to perform population genetics analyses under Linux and Windows. Mol Ecol Resour 2010;10:564-7.

31. Rousset F. GENEPOP'007: a complete re-implementation of the genepop software for Windows and Linux. Mol Ecol Resour 2008;8:103-6.

32. Bennett PH, Burch TA. The epidemiological diagnosis of ankylosing spondylitis. In: Bennett PH, Wood PHN, eds. Population studies of the rheumatic diseases. Amsterdam: Excerpta Medica, 1968: 453-8.

33. Rudwaleit M, Jurik AG, Hermann KG, et al. Defining active sacroiliitis on magnetic resonance imaging (MRI) for classification of axial spondyloarthritis: a consensual approach by the ASAS/ OMERACT MRI group. Ann Rheum Dis 2009;68:1520-7.

34. Burgos-Vargas R, Vazquez-Mellado J, Cassis N, et al. Genuine ankylosing spondylitis in children: a case-control study of patients with early definite disease according to adult onset criteria. $J$ Rheumatol 1996;23:2140-7.

35. Heuft-Dorenbosch L, van Tubergen A, Spoorenberg A, et al. The influence of peripheral arthritis on disease activity in ankylosing spondylitis patients as measured with the Bath Ankylosing Spondylitis Disease Activity Index. Arthritis Rheum 2004;51:154-9.

36. Roussou E, Sultana S. The Bath Ankylosing Spondylitis Activity and Function Indices (BASDAI and BASFI) and their correlation with main symptoms experienced by patients with spondyloarthritis. Clin Rheumatol 2010;29:869-74.

37. Reveille JD. The genetic basis of spondyloarthritis. Ann Rheum Dis 2011;70(Suppl 1):i44-50.

38. Reveille JD, Ball EJ, Khan MA. HLA-B27 and genetic predisposing factors in spondyloarthropathies. Curr Opin Rheumatol 2001;13:265-72.

39. Valle $\mathrm{R}$, Londono $\mathrm{J}$, Velez $\mathrm{P}$, et al. Outcome of patients with undifferentiated seronegative spondyloarthropathy. Arthritis Rheum 1997;40:A270.

40. Londono J, González L, Ramírez A, et al. Caracterización de las espondiloartropatías y determinación de factores de mal pronóstico en una población de pacientes colombianos. Rev Colomb Reumato 2005;12:195-207.

41. Sampaio-Barros PD, Bortoluzzo AB, Conde RA, et al. Undifferentiated spondyloarthritis: a longterm followup. J Rheumatol 2010;37:1195-9. 
42. Mielants H, Veys EM, De Vos M, et al. The evolution of spondyloarthropathies in relation to gut histology. I. Clinical aspects. J Rheumatol 1995;22:2266-72.

43. Burgos-Vargas R, Clark P. Axial involvement in the seronegative enthesopathy and arthropathy syndrome and its progression to ankylosing spondylitis. J Rheumatol 1989;16:192-7.

44. Martínez-Laso J, Herraiz MA, Vidart JA, et al. Polymorphism of the HLA-B* 15 group of alleles is generated following 5 lineages of evolution. Hum Immunol 2011;72:412-21.

45. Stein JM, Machulla HK, Smeets R, et al. Human leukocyte antigen polymorphism in chronic and aggressive periodontitis among Caucasians: a meta-analysis. J Clin Periodontol 2008;35:183-92.
46. Choukri F, Chakib A, Himmich H, et al. HLA-B* 51 and $B^{\star} 15$ alleles confer predisposition to Behcet's disease in Moroccan patients. Hum Immunol 2001;62:180-5.

47. Turnquist HR, Thomas HJ, Prilliman KR, et al. HLA-B polymorphism affects interactions with multiple endoplasmic reticulum proteins. Eur J Immunol 2000;30:3021-8.

48. McHugh K, Bowness P. The link between HLA-B27 and SpA-new ideas on an old problem. Rheumatology (Oxford) 2012;51:1529-39.

49. Chen L, Fischer R, Peng Y, et al. Critical role of endoplasmic reticulum aminopeptidase 1 in determining the length and sequence of peptides bound and presented by HLA-B27. Arthritis Rheumatol 2014:66:284-94. 